\title{
Interactive comment on "Recommendations for processing atmospheric attenuated backscatter profiles from Vaisala CL31 Ceilometers" by Simone Kotthaus et al.
}

\section{Simone Kotthaus et al.}

s.kotthaus@reading.ac.uk

Received and published: 16 June 2016

\section{Response to Anonymous Referee \#1}

We would like to thank the referee for their positive feedback and valuable suggestions to improve the manuscript. Please see comments below.

Please note that an additional dataset is included in the revised version as these observations provide additional insights on sensor-specific characteristics (e.g. the instrument-related background signal). Further, the near-range correction (Sect. 3.4) is updated in the revised version to make it more generally applicable, i.e. the new version can also handle more complex conditions. Conclusions and recommendations 
This manuscript is a very valuable contribution which helps the scientific community to better interpret CL31 ceilometer data. This interpretation has sometimes turned out not to be trivial. Therefore, the analysis and hints given here are urgently needed. I wonder whether there could be achieved a somehow better balance between the Introduction and the Conclusions. Otherwise, I recommend to publish this manuscript after minor revisions.

$\rightarrow$ We have re-written the Introduction and Summary section.

The Introduction is rather short and does not really reflect the widespread use of this type of ceilometer in scientific research. Only a few references are given. There is, e.g., a study where CL31 ceilometers are compared to older ceilometers and to temperature profiles obtained by a RASS (Emeis et al., 2009) which could be mentioned as well.

$\rightarrow$ The Introduction still focuses on the CL31 ceilometer, however, now includes references to the Emeis et al. (2009) study which compares two CL31 sensors to each other and also to an LD-40. Further we include Haeffelin et al. (2011) who compare a CL31 attenuated backscatter profile to that of a Jenoptik CHM15K and Madonna et al. (2015) who compare a Vaisala CT25K to Jenoptik and Campbell systems.

One reason why backscatter intensity from ceilometers have to be free of artefacts is that these instruments are frequently used to track the depth of the atmospheric boundary layer. The necessity could be illustrated by making reference to a paper which summarizes such tracking schemes (Emeis et al. 2008).

$\rightarrow$ The aspect of mixing height detection and implications of noise in the profile of attenuated backscatter is now included in the Introduction.

The Conclusions are rather long and therefore not really handy for the reader. Maybe, there could be made a split between more technical issues (which hardware to be

Interactive

comment

Printer-friendly version

Discussion paper 
used with which firmware) and some general conclusions being independent of specific hardware and firmware versions.

AMTD

$\rightarrow$ We have split the Summary into sections: 'Instrument-specific characteristics and issues', 'Proposed corrections', and 'Concluding recommendations'.

\section{References}

Emeis, S., K. Schäfer, C. Münkel, 2008: Surface-based remote sensing of the mixinglayer height - a review. Meteorol. Z., 17, 621-630. DOI: 10.1127/0941-2948/2008/0312

$\rightarrow$ Reference included: page 4, line 12

Emeis, S., K. Schäfer, C. Münkel, 2009: Observation of the structure of the urban boundary layer with different ceilometers and validation by RASS data. Meteorol. Z., 18, 149-154. DOI: 10.1127/0941-2948/2009/0365

$\rightarrow$ Reference included: page 3, line 22

Please also note the supplement to this comment:

http://www.atmos-meas-tech-discuss.net/amt-2016-87/amt-2016-87-AC1-

supplement.pdf

Interactive comment on Atmos. Meas. Tech. Discuss., doi:10.5194/amt-2016-87, 2016.

Discus 